\section{What Next?}

Recently, the Materials Research Society celebrated its 20th birthday. In these 20-plus years, we have grown to be a society of over 12,000 members. We hold what are arguably the two premier meetings for the international materials community. We have an active publishing enterprise, including an outstanding journal for members (MRS Bulletin), a refereed journal (Journal of Materials Research), and a series of almost 500 bound symposium proceedings. We are active in representing the materials research community in public and government affairs. We are developing initiatives in electronic communications and publishing, and in career and employment services. Recently, we concluded that renting space for our headquarters activities was too limiting, and not financially prudent. We have therefore decided to construct a new headquarters building which will serve as the fulcrum for our society operations and an important new focal point for member activities.

So what? In my mind, the important question is not where we have come from, or even where we are, but where do we want to go?

The next century has crept up upon us fast. I remember as a child trying to calculate whether I could expect to live to the year 2000. Now I have credit cards, car payments, and even research grants which expire in the next millennium. The future is upon us, and I think there is every reason to believe that we are entering a golden age for materials research. In the coming decades, we are going to see revolutionary materials concepts become commonplace. The planes we fly will be made of carbon composite materials as well as new metal alloys. Entirely new

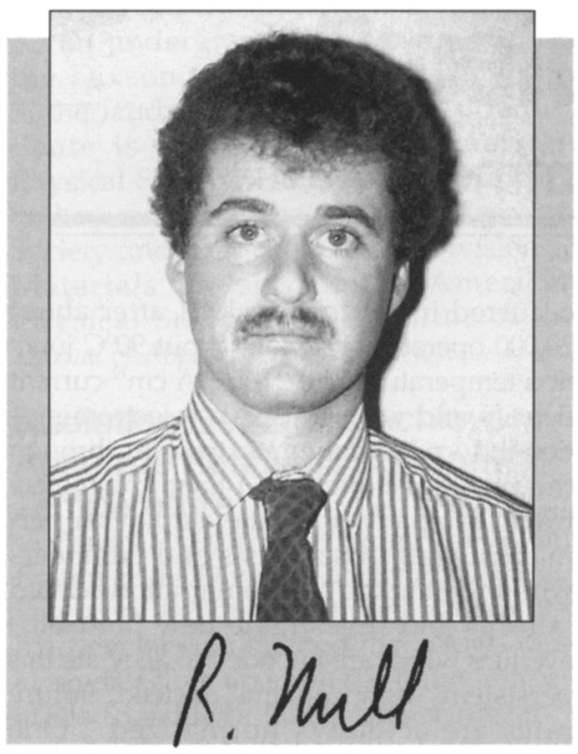

materials applications will be developed in the biomedical field. New structural, optical, and electronic applications for polymers will be explored. New materials and processes will enable the microelectronics and optoelectronics industries to continue their dazzling tradition of enormous progress and innovation. It is quite plausible that in the future historians will refer to this time as the "Materials Age."

So how does MRS respond to these enormous opportunities in order to help define and lead this Materials Age? We have evolved into a stable, secure, and effective entity. But I believe that it is critical not to stand still and ossify. We need to develop a vision for what we want MRS to become in the next decade and beyond, and then start the necessary steps to implement that vision.

A major goal of my year as president will be to guide the process to define this vision and set up the necessary mechanisms to implement it. I urge you all to give your input into this process. The kinds of questions we need to grapple with are the following: Do we want the Society to grow in membership - to double, triple, or even quintuple in size? Should we substantially expand the number of technical meetings the Society holds? Do we want to create cooperative programs with industry for our members, and should we develop professional qualifications such as are common in engineering fields? Should we increase our involvement in public, government, and academic forums? How do we best broadcast the message of the importance and universal utility of materials research? How do we foster an environment conducive to further public and government support of our enterprise?

An essential fuel for implementing any substantial initiative is the vision, enthusiasm, knowledge, and passion of volunteers. I urge all of you who feel strongly about the future of our Society - and our field - to bring your strengths and skills to this process and volunteer. Contact me, or any Society officer or committee chair (you can find all their names and contact information in the MRS Members' Directory) to let us know how you want to participate in this process.

I can be contacted by e-mail at hull@ mrs. org, or if you want to promote more general discussion, we are setting up a bulletin board at http://www.mrs.org/netforum/ mrspres/a on the World Wide Web. I look forward to hearing from you.

ROBERT HULL

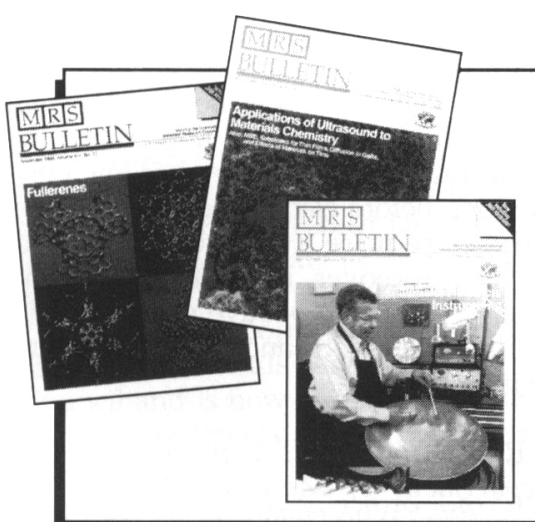

\title{
The MRS Bulletin
}

A great reason to join MRS (if you haven't already) Monthly subscription FREE with your membership! 